\title{
Health Promoting Behaviors Among Postmenopausal Women in Langroud City, Iran
}

\author{
Fahimeh Sehhatie, Mojgan Mirghafourvand, Kafiyeh Momeni*
}

\begin{abstract}
Objectives: Health promoting behaviors and healthy lifestyle are main approaches for health control. Postmenopausal women's unhealthy life style is the origin of many serious side-effects of this period. This study was carried out to determine the state of health promoting behaviors and its individual-social predictions in postmenopausal women.

Materials and Methods: In this cross-sectional study, 400 postmenopausal women at the age range of 45-60 years in Langroud city (Gilan province, Iran) were studied by random sampling. The data were collected by referring to their houses using demographic and Health-Promoting Lifestyle Profile-II (HPLP-II). Pearson test, $t$ test, one-way analysis of variance (ANOVA) and multivariate linear regression (MVR) model were used to analyze data.

Results: The mean (standard deviation) of the whole score of health promoting behaviors was $2.6(0.3)$. The highest score of life style behavioral dimensions related to spiritual growth was $3.6(0.4)$ and the lowest score was related to physical activity $1.6(0.3)$. There was a positive significant relationship between the whole score of life style level of education, body mass index, chronic diseases and salary $(P<.001)$ and significantly reverse relation with number of children $(P<.001)$.

Conclusion: The findings showed that health promoting behaviors in postmenopausal women were moderate. Therefore, certain policies should be designed and conducted to promote behaviors in in this group of women. Also more attention should be paid to their physical activity.

Keywords: Behavior, Health promotion, Postmenopause
\end{abstract}

\section{Introduction}

One of the criteria of determining health is health promoting behaviors. Both health promotion and prevention from diseases are directly in relation with these behaviors (1). According to the World Health Organization (WHO), $70 \%-80 \%$ of deaths in developed countries and $50 \%-60 \%$ in developing countries are related to life style (2). Most of the health problems such as overweight, cancer, smoking, addiction and cardiovascular diseases are related to changes in life style (3). Therefore, health promoting behaviors by emphasizing on healthy life-style would promote health, life quality and reduce costs of treatment (4). The most important emphasis of health promoting is prevention of diseases, developing skills and individual's abilities in taking care of themselves (5). Health promoting behaviors are defined as spontaneous and continuous activities that are carried out according to an active approach to promote personal welfare and self-actualization. Recognizing factors and personal characteristics have main role in the continuity of health promoting behaviors, structured interventions and controlling these behaviors (6). Health promoting behavior is a multidimensional pattern that Pender in 1996 divided it into 6 dimensions of nutrition, physical activity, spiritual growth, health responsibility, stress management, and interpersonal relations (7). Healthy life style in all stages of life, and its continuity from uterus to old age is an undeniable necessity. Paying attention to health promoting behaviors is very important in menopausal period. Although menopause is a natural stage of women's life, it is a complicate phenomenon that needs changes in living, mood, and social aspects of life (8). Studies showed the relationship between health promoting behaviors and reducing the side-effects of menopause.

Ghorbani et al (9) in investigation of health promoting behaviors and its relation with hot flashes in menopause showed that there is a relationship between health promoting behaviors and hot flashes. Moilanen et al (10) in their study, showed that athlete and nonalcoholic women experience less side-effects of menopause in comparison with nonathlete and alcoholic postmenopausal women. As women have main role in family and society, coping with these roles and duties requires physical and mental health. So, women in menopause should be familiar with dimensions of healthy life style and be informed of applying healthy promoting behaviors strategies and their roles in controlling signs and side-effects of menopause.

Unstable and unhealthy life style in long term will be a 
serious threat for postmenopausal women and they will face chronic diseases, vulnerability and disabilities in old age. Therefore, because of its importance, this study was carried to determine health promoting behaviors and its individual-social predictions in postmenopausal women living in Langroud city (Gilan, Iran).

\section{Material and Methods}

Type of Study and Method of Sampling

This is an analytical-descriptive cross-sectional study performed on postmenopausal women living in Langroud in 2013. Method of sampling was cluster sampling. Initially, with the help of the Statistical Center of Langroud city, based on the population and housing census of 2011, 80 middle-aged (range: 45-60 years) women's addresses were randomly selected as cluster heads from among 8000 postmenopausal women that were target group. Sampling began from cluster heads and continued by moving to complete 5 individuals in each 80 clusters and data were collected from 400 individuals. Sample size, considering $5 \%$ error, 0.05 accuracy and standard deviation of whole score of health promoting behaviors in the study by Enjezab et al (11) which was 0.36, was about 199 individuals. Considering the design effect equal to 2 , sample size for this study was about 400 individuals.

\section{Tools of Study}

Demographic questionnaires of Health-Promoting Lifestyle Profile-ll (HPLP-ll) of middle-aged women were used to collect data. Demographic characteristics consisted of questions on age, age of menopause, body mass index (BMI), education, marital status and number of children, number of family members, employment and economic, life and chronic diseases.

HPLP-ll questionnaire was designed by Walker et al (6) in 1987 to investigate health promoting behaviors and its validity and reliability were measured in Iran in the study by Enjezab et al (11). It includes 70 questions that investigate health promoting behaviors of middle-aged women. The questions, based on Likert scale, were designed from "never" to" sometimes", "often," and "always" with the score of 1 to 4 and all the questions were positively designed.

To determine the validity of tools, face validity and content validity were used. Pre-test and re-test were used on 30 individuals to determine the reliability of the instrument reproducibility and correlation. 95\% confidence interval and Cronbach alpha for health promoting life style were respectively ( $87 \%$ to $97 \%$ ) $88 \%$ to $93 \%$. The questionnaires were completed by interview.

\section{Data Analysis}

To analyze data, SPSS 13 was used. To describe demographic characteristics and health promoting behaviors, descriptive statistics such as absolute and relative frequency distribution, central and dispersion scales such as mean and standard deviation were used. To analyze the relationship between health promoting behaviors and demographic characteristics, $t$ test, Pearson test and one- way analysis of variance (ANOVA) were used. Then, to control confounding variables and evaluate the effect of each independent variables (demographic characteristics) on dependent variables (health promoting life style) and expressing variance, those independent variables in which their $P$-values in 2 variable tests were less than 0.2 , were entered into multivariate linear regression by backward strategy. $P$-value less than 0.05 are considered significant.

\section{Results}

\section{Demographic Characteristics}

Demographic characteristics of women participating in research are shown in Table 1. Mean (standard deviation) of age and menopausal age were respectively 53.5 (3.5) and 48.4 (2.2). Almost one fourth of women were fat and their BMIs were 30 and more, and also half of the women suffered from at least one chronic disease. About half of the women's education was elementary school. More than $90 \%$ of women were married, more than half had 3 to 4 children. Also $74.7 \%$ of women were housewives and economic status of $75.3 \%$ of individuals was sufficient. More than half of the individuals were satisfied with their life.

\section{Health Promoting Behaviors}

Mean and standard deviation of the whole score of health promoting behaviors and its subdomains are shown in Table 2. Mean and standard deviation of life style in postmenopausal women were $2.6(0.3)$ and the highest score of life style behavior was related to spiritual growth 3.6 (0.4) and the lowest score was related to physical activity $1.6(0.3)$.

\section{Health Promoting Life Style}

According to the results of 2 available tests, there were significant statistical relationships between BMI, education, marital status, number of children, life satisfaction, chronic diseases and health promoting life style $(P<.05$; Table $2)$. The mentioned variables and economical variable that had $P<.2$ were entered into multivariate regression model by backward strategy. Finally, the variables of BMI, education, number of children, economic status and chronic diseases remained in the model and could explain 13.2\% of observed variance in the whole score of health promoting life style (Table 3).

\section{Nutrition}

There was a significant statistical relationship $(P<.05)$ between nutrition and menopausal age, marital status, number of children and economic status. The mentioned variables were entered into multivariate regression test, backward model. Finally, variables of BMI, marital status and number of children remained in the model that altogether explained $3.2 \%$ of variance in mean scores of this subdomain.

\section{Physical Activity}

There was a significant statistical relationship between physical activity and variables of menopausal age, edu- 
Table 1. Demographic Characteristics and Their Relationships With General Health Score in Postmenopausal Women

\begin{tabular}{|c|c|c|c|}
\hline Variable & No. (\%) & Mean (SD) & $P$ \\
\hline Age & & & .721 \\
\hline 50 and less & $101(25.3)$ & $2.6(0.3)$ & \\
\hline $50-55$ & $184(46.0)$ & $2.6(0.3)$ & \\
\hline More than 55 & $115(28.7)$ & $2.6(0.5)$ & \\
\hline Menopause age & & & .067 \\
\hline 45-50 year & $330(82.5)$ & $2.6(0.2)$ & \\
\hline 50 and more & $70(17.5)$ & $2.6(0.3)$ & \\
\hline BMI $\left(\mathrm{kg} / \mathrm{m}^{2}\right)$ & & & .021 \\
\hline Less than 18.5 & $2(0.5)$ & $2.5(0.0)$ & \\
\hline $18.5-24.99$ & $75(18.8)$ & $2.5(0.3)$ & \\
\hline $25-29.99$ & $224(56.0)$ & $2.6(0.2)$ & \\
\hline 30 and more & $99(24.7)$ & $2.6(0.3)$ & \\
\hline Education & & & .002 \\
\hline Elementary school & $170(42.5)$ & $2.5(0.3)$ & \\
\hline Guidance school & $37(18.8)$ & $2.6(0.2)$ & \\
\hline High school & $74(56.0)$ & $2.5(0.2)$ & \\
\hline Diploma and university & $119(29.7)$ & $2.7(0.3)$ & \\
\hline Marital status & & & .003 \\
\hline Married & $363(90.8)$ & $2.6(0.2)$ & \\
\hline Divorced and widow & $37(9.2)$ & $2.5(0.2)$ & \\
\hline No. of children & & & .001 \\
\hline 2 and less & $131(32.75)$ & $2.6(0.2)$ & \\
\hline $3-4$ & $219(54.75)$ & $2.6(0.2)$ & \\
\hline More than 5 & $50(12.5)$ & $2.4(0.4)$ & \\
\hline No. of family members & & & .857 \\
\hline $1-3$ & $319(79.7)$ & $2.6(0.3)$ & \\
\hline More than 3 & $81(20.3)$ & $2.6(0.3)$ & \\
\hline Sadat status & & & .700 \\
\hline Sadat & $46(11.5)$ & $2.5(0.2)$ & \\
\hline Non-Sadat & $354(88.5)$ & & \\
\hline Employment status & & & .300 \\
\hline Housewife & $339(74.7)$ & $2.6(0.3)$ & \\
\hline Employed & $161(15.3)$ & $2.6(0.3)$ & \\
\hline Economic status & & & .083 \\
\hline Less than sufficient & $99(24.7)$ & $2.5(0.3)$ & \\
\hline Sufficient ${ }^{\mathrm{a}}$ & $301(75.3)$ & $2.6(0.2)$ & \\
\hline Life satisfaction & & & .001 \\
\hline Not satisfied & $27(6.7)$ & $2.3(0.2)$ & \\
\hline Satisfied & $161(53)$ & $2.6(0.3)$ & \\
\hline No opinion & $212(40.3)$ & $2.6(0.3)$ & \\
\hline Having chronic diseases & & & .006 \\
\hline Yes & $233(58.2)$ & $2.6(0.3)$ & \\
\hline No & $167(41.8)$ & $2.6(0.2)$ & \\
\hline
\end{tabular}

${ }^{a}$ As a number of individuals with university degrees were 12 and widows were 2 and also the number of individuals with income more than sufficient was 1 , they were merged with their previous group. Number of single individuals were 2.

cation, number of children, life satisfaction and chronic diseases $(P<.05)$. The mentioned variables were entered into multivariate regression test, backward model. Finally, the variables of menopausal age, education, number of children and life satisfaction remained in the model and could explain $10.1 \%$ of variance in the mean scores of this subdomain.

Spiritual Growth

There was a significant statistical relationship $(P<.05)$ be-
Table 2. Mean and Standard Deviation (SD) of Whole Score of Life Style and Their Subdomains in Postmenopausal Women

\begin{tabular}{lccc}
\hline Variable & Mean (SD) & $\begin{array}{c}\text { Observed } \\
\text { Scientific Domain }\end{array}$ & $\begin{array}{c}\text { Possible } \\
\text { Domain }\end{array}$ \\
\hline Life style & $2.6(0.3)$ & $1.4-3.6$ & $1-4$ \\
Nutrition & $2.6(0.4)$ & $1.0-3.8$ & $1-4$ \\
Physical activity & $1.6(0.3)$ & $1.0-3.2$ & $1-4$ \\
Spiritual growth & $3.6(0.4)$ & $1.5-4.0$ & $1-4$ \\
Health responsibility & $2.2(0.4)$ & $1.1-3.8$ & $1-4$ \\
Stress management & $2.6(0.5)$ & $1.0-4.0$ & $1-4$ \\
Individual's & $3.2(0.4)$ & $1.4-4.0$ & $1-4$ \\
relationships & & & \\
\hline
\end{tabular}

Table 3. The Relationship Between Demographic Characteristics and Whole Score of Life Style in Postmenopausal Women Based on Multivariate Linear Regression Test ${ }^{\mathrm{a}}$

\begin{tabular}{|c|c|c|}
\hline Variable & $\beta(95 \% \mathrm{Cl})$ & $P$ \\
\hline \multicolumn{3}{|l|}{ BMI $\left(\mathrm{kg} / \mathrm{m}^{2}\right)$} \\
\hline 18.5-24.99 (reference) & 0 & \\
\hline Less than 18.5 & 0.016 (0.34 to 0.48$)$ & .736 \\
\hline $25-29.99$ & 0.15 (0.02 to 0.17$)$ & .014 \\
\hline 30 and more & $0.16(0.02$ to 0.20$)$ & .01 \\
\hline \multicolumn{3}{|l|}{ Education } \\
\hline $\begin{array}{l}\text { Diploma and university } \\
\text { (reference) }\end{array}$ & 0 & \\
\hline Elementary school & $-0.13(-0.15$ to 0.01$)$ & .025 \\
\hline Guidance school & $-0.06(-0.17$ to 0.04$)$ & .226 \\
\hline High school & $-0.19(-0.23$ to -0.06$)$ & .000 \\
\hline \multicolumn{3}{|l|}{ No. of children } \\
\hline More than 5 (reference) & 0 & \\
\hline Less than 2 & 0.25 (0.06 to 0.26$)$ & .001 \\
\hline $3-4$ & $0.34(0.12$ to 0.30$)$ & .000 \\
\hline \multicolumn{3}{|l|}{ Economic status } \\
\hline Less than sufficient (reference) & 0 & \\
\hline Sufficient & $0.18(0.06$ to 0.20$)$ & .000 \\
\hline \multicolumn{3}{|l|}{ Having chronic diseases } \\
\hline No (reference) & 0 & \\
\hline Yes & 0.11 (0.01 to 0.13$)$ & .018 \\
\hline
\end{tabular}

${ }^{a}$ Adjusted $R^{2}=13.2 \%$

tween spiritual growth and variables of age, menopausal age, education, number of children, economic status and life satisfaction. The mentioned variables were entered into multivariate regression test, backward model. Finally, the variables of menopausal age, education, number of children and economic status remained in the model and altogether explained $13.6 \%$ of variance in the mean scores of this subdomain.

Health Responsibility

There was a significant statistical relationship $(P<.05)$ between health responsibility and variables of menopausal age, education, marital status, number of children and employment status. The mentioned variables were entered into multivariate regression test with backward strategy and finally the variables of menopausal age, education and number of children remained in the model and could explain $6.6 \%$ of variance in the mean scores of this subdomain. 


\section{Stress Management}

There was a significant statistical relationship $(P<.05)$ between stress management and variables of education, marital status, employment status and life satisfaction. The mentioned variables were entered into multivariate regression test with backward strategy and finally the variable of education remained in the model and could explain 5.35 of variance in the mean scores of this subdomain.

The Relationship Between Individuals

There was a significant statistical relationship $(P<.05)$ between individuals' relationships and variables of age, BMI, number of children, economic status, life satisfaction and chronic diseases. The mentioned variables were entered into multivariate regression test with backward strategy. Finally, the variables of BMI, number of children, economic status and chronic diseases remained in the model that altogether explained $7.7 \%$ of variance in the mean scores of this subdomain.

\section{Discussion}

This study was carried out by the purpose of determining health promoting behaviors and its individual-social predictions in postmenopausal women in Langroud city. It was clear that in this research postmenopausal women had an average life style. This study was in concordance with the study by and Enjezab et al (11) in Iran. In comparison with the Korean middle-aged women (12) and Turkish worker women (13), the samples of this study were in better situation.

In this study, the highest mean score of participants was related to spiritual growth. This result was in concordance with the study by Enjezab et al (11) among middle-aged women and Tol et al (14) in students.

In our study, the score of spiritual growth was more, in comparison with the study by Lee et al (15) conducted in Taiwan, which could be due to main role of religion in Iran. Spiritual growth is one of the important aspects of life and determines human's goals in life and increases his/ her ability to improve his/her health. It increases human's satisfaction with life (16). Spirituality is determined by the characteristics such as stability in life, close relationship with God and society and also individual's good relation with himself/herself (17).

In this study women had the lowest score in physical activities. This was similar to the study by Enjezab et al. conducted on middle-aged women (11) and Mahmoodabad et al (18) performed on professors of Yazd University of Medical sciences (18). In the study conducted by Duffy et al (19) and Pender et al (20) in America, the participants' physical activities was better.

It is clear that physical activities are necessary in all individuals especially in middle-aged women and inadequate physical activity causes cardiovascular diseases, diabetes and osteoporosis (21). In this study, $24.7 \%$ of women were fat, had BMI of more than 30 (that could be due to lack of physical activities) and chronic diseases. The result of lack of physical activity in our society may be the lack of wom- en's positive belief and attitude toward physical activity. Experts believe that if an individual has positive attitude toward one behavior, he/she will do that (22). The participants' health responsibility scores, in our study, were low and these results were in concordance with many studies (11). It is maybe because of individuals did not consider their health control as a necessity. Naturally, an individual will not do anything to promote his/her health unless he/ she has problem with it (23).

In this study, educational level was one of the effective factors in health promoting behaviors; women with higher educational level had better status which is in concordance with other studies $(9,11,15)$. In this study, with increase in the number of children, health promoting life style status got poor, which was in concordance with the study by Enjezab et al (11). but Ghorbani et al (9) did not report significant statistical relationship in their study. Perhaps women with more children in comparison with women with fewer children have less time to take care of themselves.

In this study, the whole score of life style among individuals increased with the increase in BMI. This could be because of the overweight issue and its associated side-effects, as such women might have completely faced the problems and diseases caused by it and thus are looking for a solution. Also, in this study, individuals with chronic diseases had better scores considering health promoting behaviors that can be because of experiencing the disease and understanding the importance of taking care of themselves. These results were in concordance with the study by Chaisiri (24).

In this study, there was a positive significant relationship between the economic status and the whole score of life style. This finding was in concordance with the studies conducted by Ghorbani et al (9), Weitzel (25), and Esin (26) but not with the study done by Pender et al (20). This could represent that adequate income is the cause of the individual's effective use of health care services. Also financial stability has positive effect on health promoting behaviors such as using appropriate sport facilities and having healthy nutrition.

\section{Conclusion}

The results of the study showed that postmenopausal women's health promoting life style status was average. Women's highest mean scores were in spiritual growth and lowest mean scores were in physical activity. Sedentary life style is an important threat to middle-aged and postmenopausal women. It is necessary to have a regular plan for exercise in order to be healthy in old age. Regular exercise plan will reduce the incidence of chronic diseases such as blood pressure, diabetes, cardiovascular diseases and will also reduce spiritual-social side-effects that will appears with aging. Therefore, one of the most important duties of health center staffs especially midwives who are responsible for taking care of postmenopausal women is to explain health promoting behaviors in addition to designing and performing educational interventional plans 
to create motivation toward healthy life style.

\section{Ethical issues}

Ethical clearance was obtained from the Ethics Committee of Tabriz University of Medical Sciences.

\section{Financial Support}

Not applicable.

\section{Conflict of Interests}

Authors declare that there is no any conflict of interest.

\section{Acknowledgments}

This research has been authorized by Tabriz University of Medical Sciences and confirmed by Ethical Committee (code of 91220 in 21 March 2013). Appreciation goes to all the participants and also to Research Deputies of Tabriz University of Medical Sciences and Gilan University of Medical Sciences who helped us in this study.

\section{References}

1. Andrews GR. Promoting health and functioning in an aging population. BMJ. 2001; 322(7288):728-729.

2. Dickey RA, Janick JJ. Lifestyle modifications in the prevention and treatment of hypertension. Endocr Pract. 2001;7(5):392-399.

3. Mohammadi A, Fatemi S. The relationship between lifestyle and public health students at Rasht University of medical sciences in 2007. J Mazandaran University Med Sci. 2007;1(1):40-45.

4. Han U. Health promoting behavior and quality of life of chronic illness in Korea. http://www./nursing Library .org $/$ portal $/ \mathrm{main}$.aspx? pageid= $4024 \& \mathrm{pid}=2141$. Accessed Jan 5, 2011.

5. Maher D, Harries AD, Zachariah R, Enarson D. A global framework for action to improve the primary care response to a chronic non-communicable diseases: a solution to a neglected problem. BMC Public Health. 2009;9:355. doi:10.1186/1471-2458-9-355.

6. Walker SN, Sechrist KR, Pender NJ. The healthpromoting lifestyle profile: Development and psychometric characteristics. Nurs Res. 1987;36(2):7681.

7. Pender NJ, Murdaugh CL, Parsons MA. Health Promotion in Nursing Practice. 4th ed. New Jersey: Prentice Hall PTR; 2005.

8. Fallahzadeh H. Quality of life after the menopause in Iran. A population study. Qual Life Res. 2010;19(6):809813. doi:10.1007/s11136-010-9644-2.

9. Ghorbani M, Azhari S, Esmaeili H, Alighanbari B. The survey of relationship between health promotion behaviors and vasomotor's symptoms in menopausal women in Mashhad, Iran. IJOGI. 2012;15(39):23-30.

10. Moilanen J, Aalto AM, Hemminki E, Aro AR, Raitanen J, Luoto R. Prevalence of menopause symptoms and their association with lifestyle among Finnish middle-aged women. Maturitas. 2010;67(4):368-374. doi:10.1016/j. maturitas.2010.08.007.
11. Enjezab B, Farajzadegan Z, Taleghani F. Aflatoonian A, Morowatisharifabad MA. Health promoting behaviors in a Population-based sample of middle-aged women and its relevant factors in Yazd, Iran. Int J Prev Med. 2010;3(Suppl 1):191-198.

12. Shin HS, Lee J, Lee KH, Song YA. Health behavioral patterns associated with psychologic distress among middle-aged Korean women. Asian Nurs Res (Korean Soc Nurs Sci). 2007;1(1):61-67.

13. Beser A, Bahar Z, Bykkaya D. Health promoting behaviors and factors related to lifestyle among Turkish workers and occupational health nurses' responsibilities in their health promoting activities. Ind Health. 2007;45(1):151159.

14. Tol A, Tavassoli E, Shariferad GR, Shojaeizadeh D. The relation between health-promoting lifestyle and quality of life in undergraduate students at school of health, Isfahan University of Medical Sciences, Iran. J Health Sur. 2001;7(4):443-446.

15. Lee FH, Wang HH. A preliminary study of a healthpromoting lifestyle among Southeast Asian women in Taiwan. Kaohsiung J Med Sci. 2005;21(3):114-120.

16. Al Ma'aitah R, Haddad L, Umlauf MG. Health promotion behaviors of Jordanian women. Health Care Women Int. 1999;20(6):533-546.

17. Adegbola M. The relationship among spirituality, selfefficacy, and quality of life in adults with sickle cell disease. Nurs Health Sci. 2008;12:275-279.

18. Mahmoodabad MS, Fazelpour Sh, Askarshahi M. Health-promoting behaviors and psychosocial wellbeing of university Shahid Sadoqi Yazd academic staff in Iran. J Ilam Uni Med Sci. 2012;21(3):12-27.

19. Duffy ME, Rossow R, Hernandez M. Correlates of healthpromotion activities in employed Mexican American women. Nurs Res. 1996;45(1):18-24.

20. Pender NJ, Walker SN, Sechrist KR, Frank-Stromborg M. Predicting health-promoting lifestyles in the workplace. Nurs Res. 1990;39(6):326-332.

21. Ekelund U, Besson H, Luan J, et al. Physical activity and gain in abdominal adiposity and body weight: prospective cohort study in 288,498 men and women. Am J Clin Nutr. 2011;93(4):826-835. doi:10.3945/ajcn.110.006593.

22. Ghazanfari Z. The effect of TTM \& HPM to promote physical activity among diabetic women [PhD Thesis]. Tehran: Tarbiat Modarres Medical Science University; 2009.

23. Delaney FG. Nursing and health promotion: conceptual concerns. J Adv Nurs. 1994;20(5):828-835.

24. Chaisiri T. The study of health promoting behaviors of the patients with essential hypertension [unpublished Master Dissertation]. Tailand: Mahidol University; 1998.

25. Weitzel MH. A test of the health promotion model with blue collar workers. Nurs Res. 1989;38(2):99-103.

26. Esin N. Evaluation and promotion of health behaviors of industry workers [unpublished PhD Thesis]. Istanbul: Istanbul University Health Science Institut; 1997.

Copyright ( 2015 The Author(s); This is an open-access article distributed under the terms of the Creative Commons Attribution License (http://creativecommons.org/licenses/by/4.0), which permits unrestricted use, distribution, and reproduction in any medium, provided the original work is properly cited. 